\title{
Targeting Divalent Metal Ions at the Active Site of the HIV-1 RNase H Domain: NMR Studies on the Interactions of Divalent Metal Ions with RNase $H$ and Its Inhibitors
}

\author{
Jiangli Yan ${ }^{1 *}$, Haihong $\mathrm{Wu}^{1}$, Tiffany Tom ${ }^{1}$, Oleg Brodsky ${ }^{1}$, Karen Maegley ${ }^{2}$ \\ ${ }^{1}$ Oncology Chemistry Pfizer Global Research and Development, La Jolla Laboratories, \\ Science Center Drive, San Diego, USA \\ ${ }^{2}$ Oncology Research Unit, Pfizer Global Research and Development, La Jolla Laboratories, \\ Science Center Drive, San Diego, USA \\ E-mail: jiangli.yan@pfizer.com
}

Received June 27, 2011; revised July 3, 2011; accepted August 22, 2011

\begin{abstract}
HIV-1 reverse transcriptase (RT) RNase H (HIV-RH) is a key target of anti-AIDS drugs. Metal-chelating compounds are an important class of chemicals in pharmacological drug discovery, especially in relation to HIV-RT and the highly-related HIV-integrase. The correlation between the metal-chelating properties and enzyme activities of the metal chelators is always of high scientific interest, as an understanding of this may accelerate the rational optimization of this class of inhibitors. Our NMR data show that $\mathrm{Mg}^{2+}$ and $\mathrm{Ca}^{2+}$ bind specifically to the active site of the RNase $\mathrm{H}$ domain and two $\mathrm{Mg}^{2+}$ ions sequentially bind one molecule of RNase $\mathrm{H}$. We also demonstrate here, using saturated and unsaturated tricyclic $N$-hydroxypyridones designed to block the active site, that the primary binding sites and affinities of divalent metal ions are correlated with the structures of the chelating motifs. Chemical shift perturbation studies of protein/metal-ion/compound ternary complexes also indicate that divalent metal ions play important roles for the specific interaction of the compounds with the RNase $\mathrm{H}$ active site.
\end{abstract}

Keywords: Metal Chelation, HIV-1, Reverse Transcriptase, RNase H, NMR Spectroscopy

\section{Introduction}

HIV-1 reverse transcriptase [1] converts single-stranded retroviral RNA into double-stranded DNA, which is integrated into the cellular genome [2-4]. HIV-1 RT is a multifunctional enzyme that has RNA-directed DNA polymerase, DNA-directed DNA polymerase and ribonuclease $\mathrm{H}(\mathrm{RNase} \mathrm{H})$ activities [1]. HIV-1 RT is a heterodimer composed of two peptide subunits, p66 and p51. The polymerase active site is located at the $\mathrm{N}$-terminus of the p66 subunit, whereas its C-terminal end contains the RNase $\mathrm{H}$ active domain [5]. The RNase $\mathrm{H}$ domain of HIV-1 RT (HIV-RH) plays a role in many steps of reverse transcription, such as the generation of an RNA primer for synthesis of the (+)-strand DNA, the degradation of the viral genomic RNA in the intermediate RNA.DNA hybrid, and the removal of host tRNA and plus-strand primers $[2,6,7]$. HIV-RH forms a central five-stranded $\beta$-sheet surrounded by four $\alpha$-helices. The core domain of the RNase $\mathrm{H}$ active site contains a highly-conserved DEDD motif that consists of four acidic residues, D443, E478, D498, and D549 [5,7]. The hydrolysis of the scissile phosphodiester bonds catalyzed by RNase $\mathrm{H}$ requires divalent metal ions, preferably $\mathrm{Mg}^{2+}[6,8]$. However, there has been some controversy regarding the number of metal ions (one or two) involved in the catalysis. Crystallographic studies of both E. coli RNase $\mathrm{H}$ and HIV-RH have shown that the active site can bind two $\mathrm{Mn}^{2+}$ ions separated by approximately $4 \AA$ and the authors proposed a two-metal-ion catalytic mechanism $[9,10]$. The ability of HIV-RH to bind to two metal ions, either two $\mathrm{Mn}^{2+}$ or two $\mathrm{Mg}^{2+}$, has also been confirmed by calorimetry and NMR, respectively $[9,11]$. However, this result was not supported by the crystal structure of the E. coli enzyme, in which only a single bound $\mathrm{Mg}^{2+}$ ion was identified (even though the crystal was obtained in high concentration of $\mathrm{MgSO}_{4}$ ) [12]. Recently, two $\mathrm{Mg}^{2+}$ ions were also observed $\sim 4 \AA$ apart in 
Bh-RNase HC-substrate complexes by Nowotny et al. $[6,8]$. Later analysis by the same group also strongly supported the two-metal-ion catalytic mechanism $[6,13]$.

The RNase $\mathrm{H}$ activity of HIV-RH plays a crucial role in the retroviral life cycle [14]. Defective mutations of two key residues (E478Q and H539F) in the RNase H domain induce a marked reduction in viral proliferation [15], thus making HIV-RH an attractive chemotherapeutical target for anti-HIV drugs [16,17]. Designing metal-chelating compounds that are able to bind two divalent metal ions at the active site is one strategy that enables the direct blocking of the active site. Small $\mathrm{N}$-hydroxyimide analogs that are optimized to bind two divalent metal ions at a $4 \AA$ distance between the ions inhibit HIV-RT activity in vitro with an $\mathrm{IC}_{50}<1.0 \mathrm{uM}$ [10]. Metal-chelating compounds are an important class of chemicals in pharmacological drug design, especially when targeted against proteins with metal ions at their active sites [4]. Metal-binding property of the metalchelators affects the potency of enzyme inhibitors, and the correlation between metal-chelation affinities and enzyme inhibition is always of interest in the design of metal-chelating inhibitors.

In this report, we applied NMR analytical methodology to study the interactions of the divalent metal ions $\mathrm{Mg}^{2+}$ and $\mathrm{Ca}^{2+}$ with HIV-RH and chemically-engineered metal-chelating compounds. When the $\mathrm{pH}$ and ionic strength are carefully maintained, we observed clean chemical shift perturbations at the active site of RNase $\mathrm{H}$ with both $\mathrm{Mg}^{2+}$ and $\mathrm{Ca}^{2+}$. We also used $1 \mathrm{D}{ }^{1} \mathrm{H}-\mathrm{NMR}$ to characterize the interactions between the divalent metal ions and HIV-RH inhibitors. Two chemically similar series, saturated and unsaturated tricyclic $N$-hydroxypyridones have different chelating affinities depending on the structure of the primary metal-binding sites. To understand the correlation between the metal-chelating properties and the inhibition of the enzyme by metalchelating inhibitors, we also studied the HIV-RH/ $\mathrm{Mg}^{2+}$ / inhibitor ternary complexes using a saturated tricyclic $N$-hydroxypyridone and $\beta$-thujaplicinol as the tool compounds.

\section{Material and Methods}

\subsection{Protein Preparation}

A cDNA fragment encoding the C-terminal domain of HIV-1 p66 protein (W426 to L560) was cloned into pET-28a in fusion with a C-terminal His $_{6}$-tag. BL21 (DE3)-AI cells transformed with the recombinant plasmid were grown at $37^{\circ} \mathrm{C}$ in $2 \mathrm{~L}$ Celtone- $\mathrm{N}$ or Celtone- $\mathrm{CN}$ media (Cambridge Isotope Laboratories, Andover, MA) to produce ${ }^{15} \mathrm{~N}$ - or ${ }^{13} \mathrm{C} /{ }^{15} \mathrm{~N}$-enriched proteins, respec- tively. After three hours, the cultures were allowed to equilibrate to $15^{\circ} \mathrm{C}-18^{\circ} \mathrm{C}$. Expression of HIV-RH was then induced using $100 \mathrm{uM} \mathrm{IPTG}$ and $0.01 \%$ arabinose at 0.7 - $1.0 \mathrm{OD}_{600}$ cell density. The cells were grown at $15^{\circ} \mathrm{C}-18^{\circ} \mathrm{C}$ for 16 hours and harvested by centrifugation. The frozen cells were resuspended and lysed in $50 \mathrm{mM}$ Tris-HCl buffer ( $\mathrm{pH} 8.0$ ) containing $250 \mathrm{mM} \mathrm{NaCl}, 100$ ul/L benzonase (Novagen), $0.2 \mathrm{mg} / \mathrm{ml}$ lysozyme (Sigma, L-6876), and 0.25 $\mathrm{mM}$ TCEP (Pierce). The His ${ }_{6}$-tagged protein was purified from the cell lysate using immobilized metal affinity chromatography (ProBond resin, Invitrogen). The eluate fraction (step elution, OmniPrep gravity column, BioRad) was further purified using size-exclusion chromatography $(100 \mathrm{~mL}$ Phenomenex S3000 column) with a mobile phase containing $25 \mathrm{mM} 1$, 3-bis(tris(hydroxymethyl)methylamino)propane (bis-Tris propane, $\mathrm{pH} 6.5$ ), $150 \mathrm{mM} \mathrm{NaCl}, 2 \%$ glycerol, and 0.25 $\mathrm{mM}$ TCEP. The desired fractions were pooled and concentrated to $15-20 \mathrm{mg} / \mathrm{ml}$ using centrifugal concentrators (Millipore).

\subsection{Backbone Resonance Assignment of HIV-RH}

All of the experiments for the resonances assignment were recorded at $30^{\circ} \mathrm{C}$ on a Bruker Avance $700 \mathrm{MHz}$ spectrometer equipped with a TCI cryo-probe. The NMR sample contained $0.9 \mathrm{mM}{ }^{13} \mathrm{C},{ }^{15} \mathrm{~N}$-labeled HIV-RH in 25 $\mathrm{mM}$ bis-Tris- $d_{14}$ (pH 6.5), $150 \mathrm{mM} \mathrm{NaCl}, 1 \mathrm{mM}$ dithiothreitol- $d_{6}$ (DTT) and $5 \%{ }^{2} \mathrm{H}_{2} \mathrm{O}$. The backbone resonances were assigned using standard triple resonance experiments, including $\mathrm{CBCA}(\mathrm{CO}) \mathrm{NH}$, HNCACB, HNCA, [18] and $\mathrm{HN}(\mathrm{CO}) \mathrm{CA}[19]$. Sequential assignments were obtained using TopSpin 2.0 (Bruker Biospin) for spectral processing and SPARKY for sequential analysis [20].

\subsection{Metal Titration with HIV-RH and Its Inhibitors}

In the HIV-RH titration experiments, $0.5 \mathrm{M} \mathrm{MgCl}_{2}$ or $\mathrm{Ca}\left(\mathrm{NO}_{3}\right)_{2}$ was titrated into the protein solution. HIV-RH protein $(70 \mathrm{uM})$ was prepared in buffer containing 25 $\mathrm{mM}$ bis-Tris- $d_{14}(\mathrm{pH} 6.5), 150 \mathrm{mM}$ salt $\left(\mathrm{NaCl}\right.$ for $\mathrm{Mg}^{2+}$ titration and $\mathrm{NaNO}_{3}$ for $\mathrm{Ca}^{2+}$ titration, respectively), 1 mM DTT, and $5 \%{ }^{2} \mathrm{H}_{2} \mathrm{O}$. The $\mathrm{pH}$ of all reagents used in the titrations was carefully monitored and readjusted to 6.5 (if required) at each step of the titration. ${ }^{1} \mathrm{H}-{ }^{15} \mathrm{~N}$ HSQC spectra were acquired on an Inova $600 \mathrm{MHz}$ spectrometer (Varian Inc.) at $25^{\circ} \mathrm{C}$ to monitor the chemical shift changes as the metal ion concentrations increased.

In the titrations with the inhibitors, each sample was prepared independently, using identical buffer conditions (except for the concentration of the metal ions). The final 
concentration of the compound was 0.20 to $0.50 \mathrm{mM}$. $1 \mathrm{D}$ ${ }^{1} \mathrm{H}-\mathrm{NMR}$ experiments were performed using an Inova $600 \mathrm{MHz}$ spectrometer (Varian Inc.) at $25^{\circ} \mathrm{C}$. All spectra were recorded with 128 transients, a 16-ppm sweepwidth using presaturation for water suppression.

The NMR data were analyzed using ACD NMR Processor (ACD-Labs, Inc) and the total chemical shift change $\Delta \delta_{o b s}$ of the ${ }^{1} \mathrm{H}-{ }^{15} \mathrm{~N}$ cross peak was calculated according to the formula,

$$
\Delta \delta_{o b s}=\sqrt{\left(\Delta \delta_{N} \times 0.17\right)^{2}+\left(\Delta \delta_{H}\right)^{2}}
$$

where $\Delta \delta_{N}$ and $\Delta \delta_{H}$ were the chemical shift changes in ${ }^{15} \mathrm{~N}$ and ${ }^{1} \mathrm{H}$ dimensions, respectively. The co-crystal structure of HIV-RH domain protein [21] was used for chemical shift mapping.

\subsection{Calculation of the Dissociation Constants $\left(K_{d}\right)$}

In the single binding mode, one metal ion binds with one molecule of protein or metal-chelating inhibitor. When the reaction occurs under the fast exchange conditions, the observed chemical shift $\left(\delta_{o b s}\right)$ is the weighted average of the chemical shifts of the free and bound species. Therefore, the observed chemical shift change $\left(\Delta \delta_{\text {obs }}\right)$ is a function of the dissociation constant $K_{\mathrm{d}}$ [2] (Equation (2)), where $\rho_{f}$ and $\rho_{b}$ are the fractions and $\delta_{f}$ and $\delta_{b}$ are the chemical shifts of the free and bound protein or compound, respectively. $M^{0}$ and $L^{0}$ are the initial concentrations of the metal ion and the chelator (protein or ligand). The data were fit using GraphPad Prism (GraphPad Software) to determine the $K_{\mathrm{d}}$ from the chemical shift changes.

\section{Results and Discussion}

\subsection{NMR Assignments of the ${ }^{1} \mathrm{H}-{ }^{15} \mathrm{~N}$ HSQC Spectra and Flexibility at the C-Terminus of HIV-RH}

An isolated, C-terminal His $_{6}$-tagged protein that contains the C-terminal domain of HIV-RT p66 protein (W426L560) was expressed and purified in its ${ }^{15} \mathrm{~N}$-labeled or ${ }^{13} \mathrm{C} /{ }^{15} \mathrm{~N}$-labeled forms for our NMR studies. The protein was mostly well-folded as the ${ }^{1} \mathrm{H}-{ }^{15} \mathrm{~N}$ HSQC peaks were well resolved and dispersed. Backbone resonance assignments of most amino acids were obtained from the standard triple resonance experiments (data available if required). The ${ }^{1} \mathrm{H}_{-}{ }^{15} \mathrm{~N}$ HSQC peaks of 26 amino acids, not including those of the $\mathrm{His}_{6}$-tag and prolines, were not observed, most likely as a result of regional flexibility and/or signal overlapping. Most of those amino acids, i.e., N474-K476, E514-L517, A538-K540, and V548-L560, were located in loop regions and at the C-terminus. We observed and assigned three amino acids (D443, E478, and D498) of the DDED motif involved in metal binding, except D549 which is located in the flexible C-terminus of the protein. This is consistent with previous reports [22] that the C-terminus of isolated HIV-RH is highly dynamic and can adopt either an $\alpha$-helical or random coil conformations in crystal structures, depending on the crystallization conditions and the space group [23]. In solution, the C-terminus is usually disordered, but can be stabilized at high concentration of $\mathrm{Mg}^{2+}(80 \mathrm{mM})$ $[11,24]$.

We observed that the conformation, stability and activity of HIV-RH are very sensitive to $\mathrm{pH}$, ionic strength and divalent metal-ion concentration. A drop in the $\mathrm{pH}$ of the buffer from 7.0 to 5.0 induced dramatic and global shifts in the ${ }^{1} \mathrm{H}^{15} \mathrm{~N}$ HSQC spectrum, and more HSQC signals were detectable at lower $\mathrm{pH}$. Interestingly, most early structural studies of HIV-RH by NMR [25-28] and $\mathrm{X}$-ray crystallography [29-31] were carried out in acidic conditions, suggesting that the isolated HIV- RH domain is more stable at lower $\mathrm{pH}$.

\subsection{Determination of the Binding Constants $\left(K_{d}\right)$ of Divalent Metal Ions with HIV-RH}

Divalent metal ions are crucial for RNase $\mathrm{H}$ activity and contribute to the conformation and stability of the protein, especially at the C-terminus $[11,28]$. In our NMR binding study of the divalent metal ions to HIV-RH, we chose $25 \mathrm{mM}$ bis-Tris ( $\mathrm{pH}$ 6.5) containing $150 \mathrm{mM} \mathrm{NaCl}$ as our buffer to maintain $\mathrm{pH}$ and ionic strength, therefore to mitigate the effects on conformation, stability and activity of HIV-RH. The buffer was also compatible with those used in the biochemical assays. Every reagent used in the experiment was prepared in the buffer described, and the $\mathrm{pH}$ was checked in each step and adjusted when necessary.

In the metal titration experiments, we dialyzed ${ }^{15} \mathrm{~N}$ labeled HIV-RH in the described buffer. $\mathrm{MgCl}_{2}(1.0 \mathrm{M}$, prepared in the same buffer) was titrated into the protein solution to increase the $\mathrm{Mg}^{2+}$ concentration from 0 to 80 $\mathrm{mM}$. Approximately 24 peaks showed obvious shifts on the ${ }^{1} \mathrm{H}^{15} \mathrm{~N}$ HSQC spectra (Figure 1(a)). The $\mathrm{Mg}^{2+}$ dosedependent chemical shift changes $(\Delta \delta)$, calculated as weighted sums of the changes in both the ${ }^{15} \mathrm{~N}$

$$
\Delta \delta_{o b s}=\delta_{o b s}-\delta_{f}=\left(\delta_{b}-\delta_{f}\right)\left(\left[M^{0}+K_{d}+L^{0}\right]-\sqrt{\left[M^{0}+K_{d}+L^{0}\right]^{2}-4\left[M^{0} L^{0}\right]}\right) / 2 L^{0}
$$




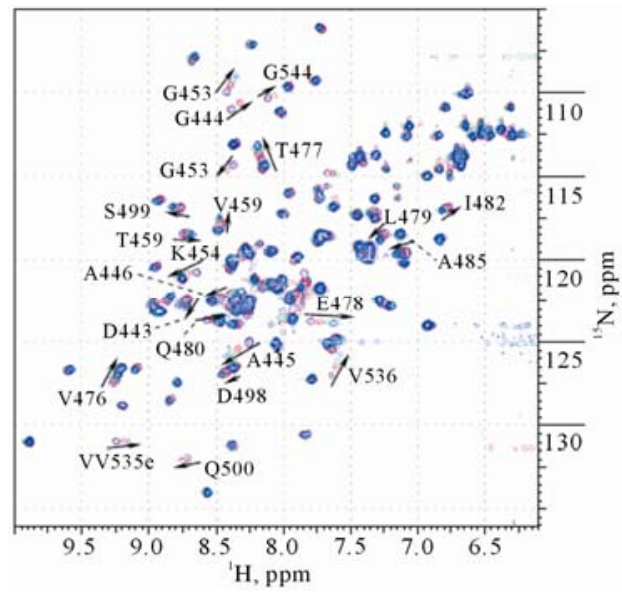

(a)

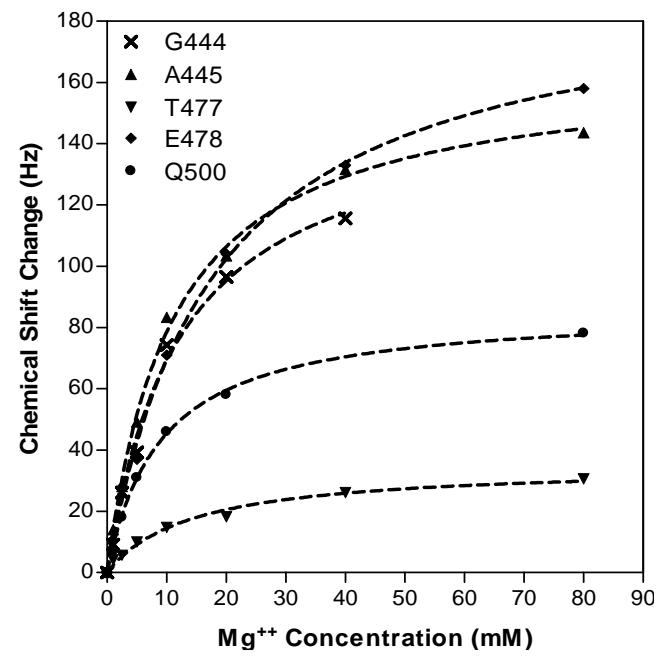

(b)

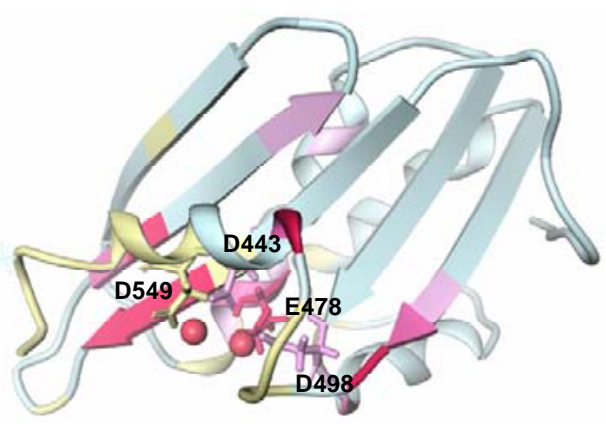

(c)

Figure 1. (a) Overlay of the HSQC spectra shows the chemical shift perturbations of HIV-RH by $\mathrm{Mg}^{2+}$ at $0 \mathrm{mM}$ (purple), $2.5 \mathrm{mM}$ (pink), $5 \mathrm{mM}$ (cyan), and $10 \mathrm{mM}$ (blue). (b) The $\mathrm{Mg}^{2+}$ titration curve of the chemical shift changes vs. the $\mathrm{Mg}^{2+}$ concentration $(0,2.5,5,10,20,40$, and $80 \mathrm{mM})$ for five selected amino acids. (c) Mapping of the shift perturbations of HIV-RH by $\mathrm{Mg}^{2+}$ at a concentration of 5.0 mM on the HIV-RH structure. Red: $\Delta \delta \geq 50 \mathrm{~Hz}$, pink: $\Delta \delta=$ 35 - $50 \mathrm{~Hz}$, light pink: $\Delta \delta \leq 35 \mathrm{~Hz}$, Yellow: not observed or assigned. and ${ }^{1} \mathrm{H}$ dimensions (Equation (1)), were fitted by Equation (2) using GraphPad Prism (GraphPad Software) as shown in Figure 1(b). It was clear that the titration curves reached a maximum plateau at about $80 \mathrm{mM}$ of $\mathrm{Mg}^{2+}$. The binding constant $\left(K_{d}\right)$ of $\mathrm{Mg}^{2+} / \mathrm{HIV}-\mathrm{RH}$ were determined by the titration data of 17 amino acids that showed $\Delta \delta>10 \mathrm{~Hz}$ with at least 6 data points. The calculated $K_{\mathrm{d}}$ ranged from 8.4 to $16.6 \mathrm{mM}$ with a goodness of fit $\left(R^{2}\right)$ from 0.984 to 0.999 . The averaged $K_{d}$ was 13 $\pm 4 \mathrm{mM}$, very similar to the value reported previously [11].

We also carried out titration experiments with stepwise increases in $\mathrm{Ca}^{2+}$ concentrations from 0 to $15 \mathrm{mM}$ in a similar fashion to those using $\mathrm{Mg}^{2+}$. We obtained a very similar pattern of chemical shift perturbations. In the plots of $\Delta \delta$ vs. the $\mathrm{Ca}^{2+}$ concentration, the titration curves reached plateaus at $15 \mathrm{mM} \mathrm{Ca}^{2+}$. The $K_{d}$ values of 21 amino acids were calculated to be in the range from 1.5 to $3.3 \mathrm{mM}$, yielding reasonable values of $R^{2}$ from 0.992 to 1.000 . The average $K_{d}$ for $\mathrm{Ca}^{2+}$ to HIV-RH is $2.9 \pm 0.5 \mathrm{mM}$, indicating that the binding of $\mathrm{Ca}^{2+}$ to HIV-RH is four times tighter than that of $\mathrm{Mg}^{2+}$.

Figure 1(c) showed the chemical shift perturbation map of $\mathrm{Mg}^{2+}$ on the HIV-RH domain protein. Amino acids at the catalytic center showed the greatest chemical shift perturbations. All three observable residues in the metal chelating DDED motif, i.e., D443, E478, and D498 stood out in the chemical shift perturbations induced by $\mathrm{Mg}^{2+} \cdot \mathrm{Ca}^{2+}$ binds to the same site as $\mathrm{Mg}^{2+}$ and amino acids located at the active site also showed the largest chemical shift changes in response to $\mathrm{Ca}^{2+}$. Our NMR titration data demonstrated small and localized chemical shift perturbation patterns in HIV-RH in response to the divalent metal ions, $\mathrm{Mg}^{2+}$ and $\mathrm{Ca}^{2+}$, when the buffer $\mathrm{pH}$ and ionic strength were carefully maintained. It is clear that $\mathrm{Mg}^{2+}$ and $\mathrm{Ca}^{2+}$ bind specifically to the active site of the RNase $\mathrm{H}$ domain, but do not significantly change the global conformation and dynamics of the protein. However, the C-terminus of our construct is still mostly disordered even at high concentrations of divalent metal ions at the testing buffer conditions. Most of the C-terminal residues of HIV-RH were not stable enough to produce measurable signals in the HSQC spectra in the presence of $80 \mathrm{mM} \mathrm{Mg}^{2+}$ or $15 \mathrm{mM} \mathrm{Ca}^{2+}$.

\subsection{Sequential Binding of $\mathrm{Two}^{\mathrm{Mg}}{ }^{2+}$ Ions to the Active Site}

In the $\mathrm{Mg}^{2+}$ titration experiments, a few peaks, including G444, Q500, W5350, and V536, became broader and broader as the $\mathrm{Mg}^{2+}$ concentration increased. More interestingly, they split into two sets of peaks at $80 \mathrm{mM} \mathrm{Mg}^{2+}$ (Figure 2(a)). The splitting of these signals indicated the 
existence of two slowly-exchanging protein conformations, and the occupancy of the second metal binding site at high $\mathrm{Mg}^{2+}$ concentrations ( $80 \mathrm{mM}$ or higher). At 80 $\mathrm{mM} \mathrm{Mg}{ }^{2+}$, the second metal-binding site was approximately half-occupied by $\mathrm{Mg}^{2+}$, whereas the first metal-binding site was almost fully occupied. Interestingly, the affinity of the second $\mathrm{Mg}^{2+}$ ion for HIV-RH was reported to be $\sim 35 \mathrm{mM}$ [11]. Figure 2(b) shows four residues with split HSQC signals at $80.0 \mathrm{mM} \mathrm{Mg}^{2+}$ in the HIV-RH structure. Three of these, Q500, W535 $\omega$, and V536, are close to D498, while D444 is on the opposite side of the active site, adjacent to D443. When the concentration of $\mathrm{Mg}^{2+}$ was $5.0 \mathrm{mM}$, large chemical shift

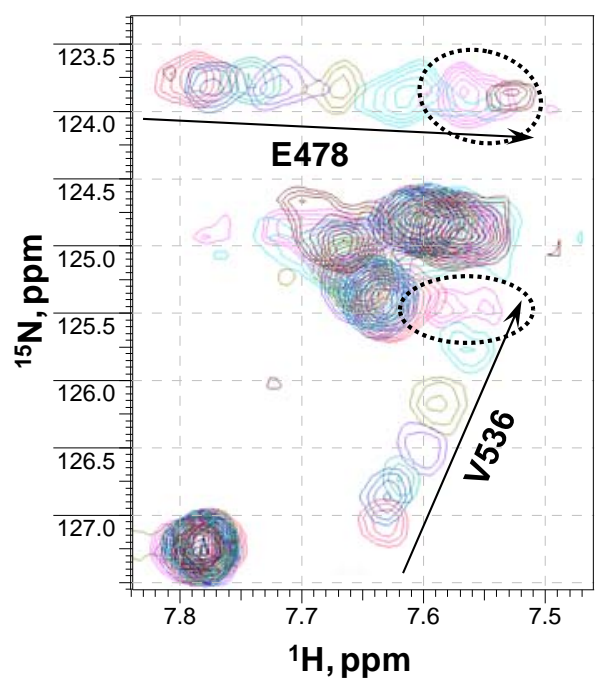

(a)

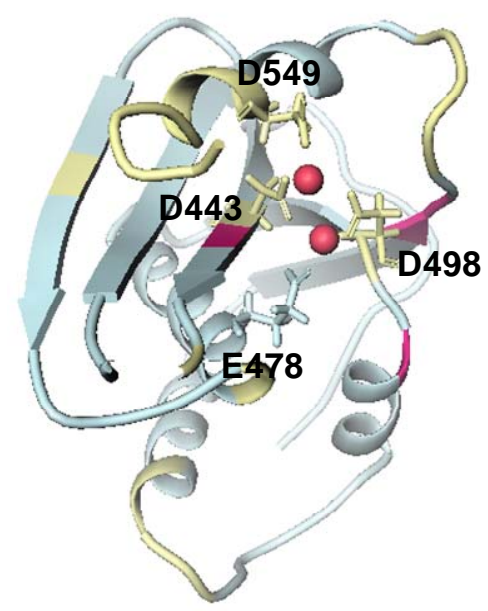

(b) changes were observed for D443 (Figure 2(c)). Our data suggest that two $\mathrm{Mg}^{2+}$ ions bind sequentially to the active site of HIV-RH. The first $\mathrm{Mg}^{2+}$ binds to site 1 and interacts with D443 and E478, whereas the second $\mathrm{Mg}^{2+}$ binds to site 2 and interacts with D498 and D549 with a slightly lower ( $\sim 3$ times) affinity (Figure $2(\mathbf{c}))$. The weaker metal binding affinity of site 2 is probably due to the flexibility of the C-terminus, where D549 is located. However, the peak splitting was not observed in the $\mathrm{Ca}^{2+}$ titration experiments. The distance between the two $\mathrm{Mg}^{2+}$ ions in the active site is $4 \AA$, as shown in the crystal structure $[8,10,11] . \mathrm{Ca}^{2+}$ has a much larger atomic radius than $\mathrm{Mg}^{2+}$; therefore, it is unlikely that two $\mathrm{Ca}^{2+}$ ions can
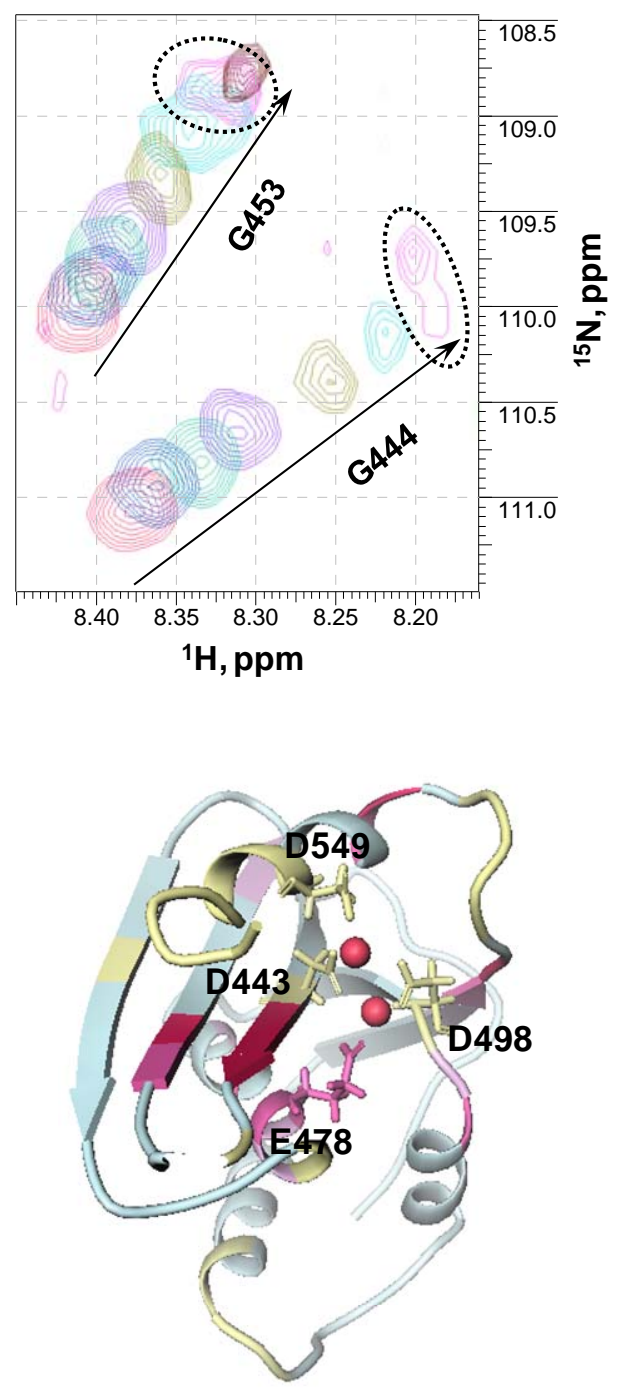

(c)

Figure 2. (a) Regions of the HSQC spectra of HIV-RH showing peak shifting with increasing $\mathrm{Mg}^{2+}$ concentrations, at 0 , 2.5, $5.0,10,20,40$, and $80 \mathrm{mM}$, in the direction indicated by the arrows. The dashed circles show peak splitting for V536 and G444 and broadening for E478 and G453 at $80 \mathrm{mM} \mathrm{Mg}^{2+}$. (b) Mapping of splitting HSQC signals on the HIV-RH structure. Red: AA with splitting HSQC signals, Yellow: not observed or assigned. (c) Mapping of the shift perturbations of HIV-RH by $5.0 \mathrm{mM} \mathrm{Mg}^{2+}$ on the HIV-RH structure as shown in Figure 2(c) in a different orientation. 
fit simultaneously into the active site. Although we saw evidence of the sequential binding of two $\mathrm{Mg}^{2+}$ ions in our experiments, we were not able to obtain enough data points to determine the binding constant of the second $\mathrm{Mg}^{2+}$ ion through curve fitting.

\subsection{Interaction of Metal-Ions to Metal-Chelating Compounds}

Divalent metal ions, especially $\mathrm{Mg}^{2+}$, are directly involved in the catalytic activities of HIV-RH, and two $\mathrm{Mg}^{2+}$ ions bind to one molecule of HIV-RH at the active site. To target the active site, it is a common strategy to design metal-chelating compounds binding to two divalent metal ions at the active site $[2,16]$. The effect of compound/metal binding property on enzyme inhibition is always of interest in the lead generation and optimization of metal-chelating compounds. In this study, we utilized 1D ${ }^{1} \mathrm{H}-\mathrm{NMR}$ experiments to identify the metalbinding sites of our lead compounds through chemical shift perturbations induced by metal ions. Again, similar to the protein/metal interaction, protons that are near the metal-binding site generally experience larger perturbations. Based on Equation (2), we determined the binding affinities of the lead compounds to metal ions through chemical shift changes. The sample preparation, data acquisition and data processing were all automated for a rapid measurement of $K_{d}$.

Derivatives of unsaturated and saturated tricyclic $\mathrm{N}$-hydroxypyridones, shown in Figures 3(a) and (b) respectively, were designed and synthesized in-house for targeting HIV-RH. The unsaturated tricyclic $N$-hydroxypyridone derivatives contain a flat and rigid three-ring core and two hypothetical metal-binding motifs (Figure 3(a)). In the $\mathrm{Mg}^{2+}$ titration experiments, all protons on the tricyclic $N$-hydroxypyridone core showed significant and incremental chemical shift changes as the $\mathrm{Mg}^{2+}$ concentration increased; the example of compound U-1 is shown in Figure 3(c). Meanwhile, only slight chemical shift changes were observed with the other protons, which were located in the R1 and R2 substitute groups. $\mathrm{H}-13$ gave the largest chemical shift changes (up to 130 $\mathrm{Hz}$ ) when the $\mathrm{Mg}^{2+}$ concentration changed. Therefore, $\mathrm{H}-13$ is the proton nearest to the $\mathrm{Mg}^{2+}$ ion (Figure 3(a)). Three more unsaturated tricyclic $N$-hydroxypyridone compounds were tested and $\mathrm{H}-13$ showed the largest chemical shift change in all cases. The chemical shift changes of the core protons at the compound $/ \mathrm{Mg}^{2+}$ ratio of 1:20 when the titration curves reached the plateaus were listed in Table 1. The chemical perturbations of the other three core protons $\mathrm{H}-5, \mathrm{H}-8$ and $\mathrm{H}-12$ showed only half of the change of $\mathrm{H}-13$. This indicates that $\mathrm{Mg}^{2+}$ preferably binds unsaturated tricyclic $N$-hydroxy-pyri- done derivatives at site $I$ by interacting with the two oxygen atoms of the $\mathrm{O}_{14} \dot{-} \mathrm{N}_{1} \dot{-} \mathrm{C}_{2} \dot{-} \mathrm{O}_{15}$ motif (Figure 3(a)). The $K_{d}$ values of the two unsaturated compounds (U-1 and U-4) were determined through chemical shift changes, and equivalent with each other within the measurement deviation range. The chelator- $\mathrm{Mg}^{2+}$ complexes of the other two compounds (U-2 and U-3) had poor solubility. As the $\mathrm{Mg}^{2+}$ concentration was approximately equivalent to the compound concentration, we saw precipitates in the NMR tubes and the proton signals became too weak to measure. Consequently, we were not able to calculate the $K_{d}$ due to the lack of points. Interestingly, when $\left[\mathrm{Mg}^{2+}\right]$ was higher than 20 times of the compound concentration, the compound proton signals became stronger and therefore measurable. The similar phenomena were also observed with compound U-1 and U-4. As shown in Figure 3(c), proton signals of U-1 became broader and broader and then sharper and sharper as the $\mathrm{Mg}^{2+}$ concentration increased gradually from 0 to $80 \mathrm{mM}$. In addition, when $\left[\mathrm{Mg}^{2+}\right]$ was over 40 times of the compound concentration, the compound proton signals shifted to an opposite direction. We believe this was related to the second metal-ion binding and the ternary complexes (compound $\left.\left(\mathrm{Mg}^{2+}\right)_{2}\right)$ had better solubility than the binary complexes (compound/ $\mathrm{Mg}^{2+}$ ). The chemical shift change "turn-over" occured all at a $\mathrm{Mg}^{2+}$ concentration of $16-20 \mathrm{mM}$, suggesting that with $\sim 20 \mathrm{mM} \mathrm{Mg}^{2+}$, the second metal-binding site is approximately half-occupied by $\mathrm{Mg}^{2+}$, whereas the first metal-binding site was almost fully occupied and therefore the $K_{\mathrm{d}}$ of the second $\mathrm{Mg}^{2+}$ to this series compound was estimated as $\sim 10 \mathrm{mM}$. In our NMR study, we could not obtain sufficient data to determine $K_{d}$ of the second $\mathrm{Mg}^{2+}$ binding using the double binding curve fit due to the maximum concentration of $\mathrm{MgCl}_{2}$ in stock solution of $0.5 \mathrm{M}$.

The observations were different when the tricyclic $N$-hydroxypyridone core was saturated at the carbon-carbon bond between C-12 and C-13 (Figure 3(b)). Saturation of the $\mathrm{C}-\mathrm{C}$ bond makes the six-member-ring more flexible and no longer flat. Figure 3(d) shows the shift of the proton signals of $0.20 \mathrm{mM}$ compound S-5 in the $\mathrm{Mg}^{2+}$ titration measurements. Table 1 lists the chemical shift perturbations of the core protons of four saturated tricyclic $N$-hydroxypyridones at a concentration ratio of compound: $\mathrm{Mg}^{2+}$ of $1: 100$ when the $\Delta \delta \mathrm{vs}$. $\left[\mathrm{Mg}^{2+}\right]$ titration curves reached the plateaus. All four saturated derivatives showed the same interaction mapping, which obviously was different from the mapping of the unsaturated analogs. Instead of $\mathrm{H}-13$ in the unsaturated cases, proton $\mathrm{H}-5$ of saturated compounds presented the largest chemical shift change, indicating $\mathrm{Mg}^{2+}$ preferably boundat site $I I$ and interacts with the nitrogen and oxygen at- 
oms of the $\mathrm{N}_{4} \div \mathrm{C}_{3}-\mathrm{C}_{2}-\mathrm{O}_{15}$ motif when the $\mathrm{C} 12-\mathrm{C} 13$ bond was saturated. In the NMR spectra, only one set of triplet peaks was observed for either of the two H-12 or two H-13 (Figure 3(d)), indicating the equivalence of the

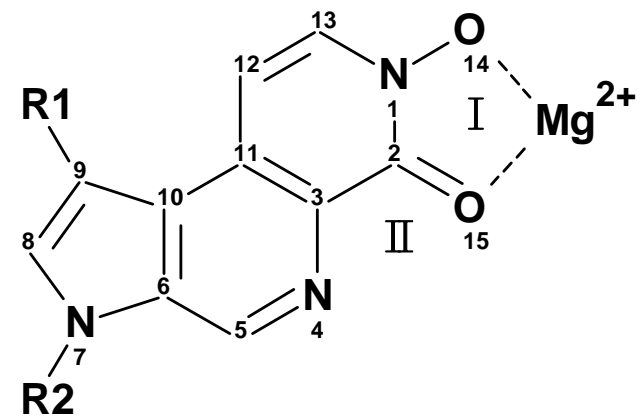

(a)

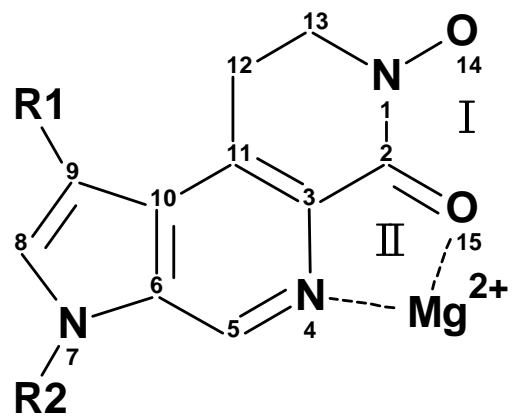

(b)

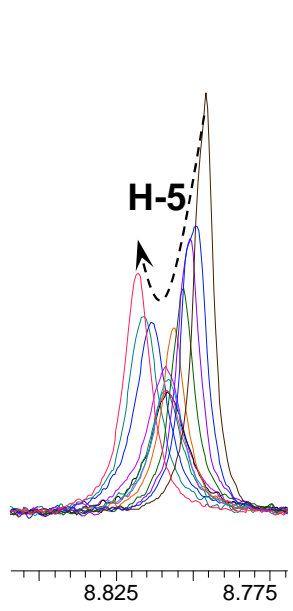

${ }^{1} \mathrm{H}, \mathrm{ppm}$

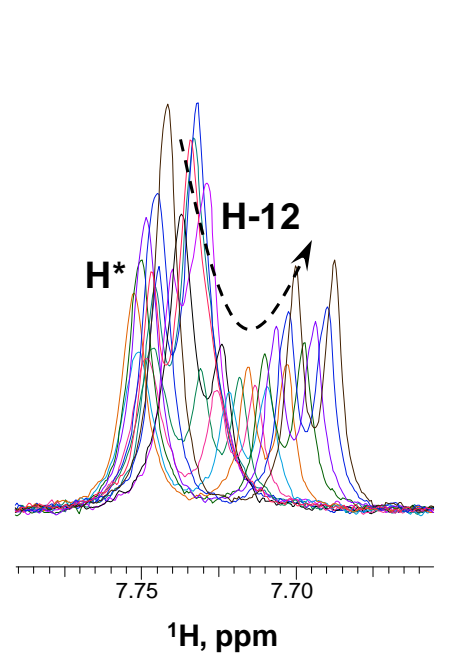

${ }^{1} \mathbf{H}, \mathbf{p p m}$

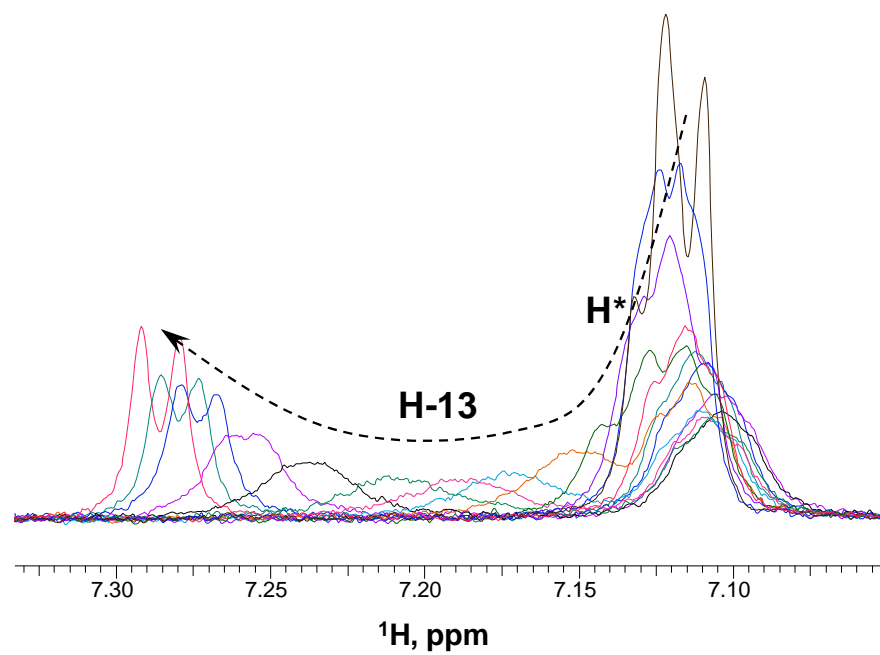

(c)

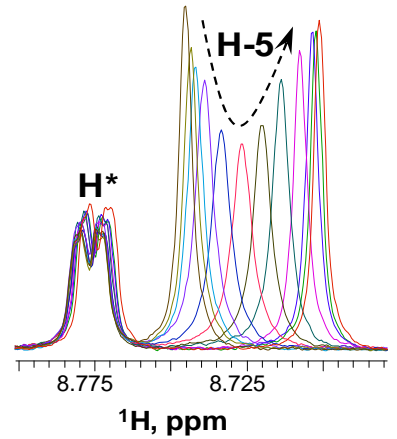

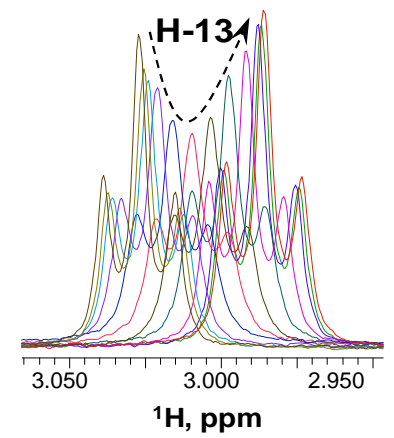

(d)

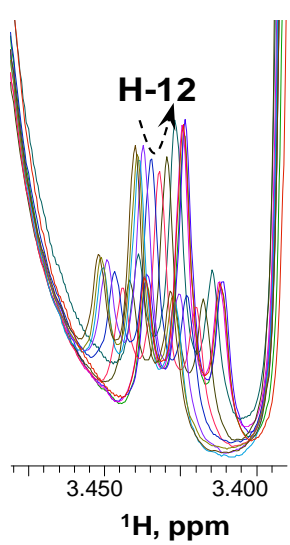

${ }^{1} \mathbf{H}, \mathbf{p p m}$

Figure 3: (a) The core structure of unsaturated tricyclic $N$-hydroxypyridones. (b) The core structure of saturated tricyclic $N$-hydroxypyridones. (c) $1 \mathrm{D}{ }^{1} \mathrm{H}$-NMR spectra of $0.50 \mathrm{mM} \mathrm{U}-1$ with $\mathrm{Mg}^{2+}$ at concentrations of $0.0,0.05,0.10,0.25,0.50,1.00$, 2.5, 5.0, 10.0, 35.0, and 50.0 mM. (d) $1 \mathrm{D}^{1} \mathrm{H}-\mathrm{NMR}$ spectra of $0.20 \mathrm{mM} \mathrm{S-5}$ with $\mathrm{Mg}^{2+}$ at concentrations of $0.0,0.2,0.4,0.8,1.6$, 3.2, 5.0, 10.0, 20.0, 40.0, and $80.0 \mathrm{mM}$. $\mathrm{R} 1$ and $R 2$ are substituent groups. Two potential metal binding motifs are labeled as $I$ $\mathrm{O}_{14}-\mathrm{N}_{1}-\mathrm{C}_{2}-\mathrm{O}_{15}$ and $\mathrm{II} \mathrm{N}_{4}-\mathrm{C}_{3}-\mathrm{C}_{2}-\mathrm{O}_{15}$. $\mathrm{Mg}^{2+}$ prefers binding to saturated tricyclic $N$-hydroxypyridones at motif $I I$, but to the saturated tricyclic $N$-hydroxypyridones at $I$. The arrows indicate the shift of the proton signals as the $\mathrm{Mg}^{2+}$ concentration increases. $\mathrm{H}^{*}$ are protons on the $\mathrm{R} 1$ or $\mathrm{R} 2$ substituents. 
Table 1. Chemical shift perturbations of unsaturated (U-1 to U-4) and saturated (S-5 to S-8) tricyclic $N$-hydroxypyridones by $\mathrm{Mg}^{2+}$ chelating.

\begin{tabular}{|c|c|c|c|c|c|c|c|}
\hline \multirow{2}{*}{ Cpd } & \multirow{2}{*}{ Cpd: $\mathrm{Mg}^{2+}$ ratio } & \multicolumn{4}{|c|}{ Chem shift changes $(\Delta \delta), \mathrm{Hz}$} & \multirow{2}{*}{$\mathrm{Mg}^{2+}$ binding $K_{d}, \mathrm{mM}$} & \multirow{2}{*}{ RNase $\mathrm{H} \mathrm{IC}_{50}, \mu \mathrm{M}$} \\
\hline & & $\mathrm{H} 5$ & H8 & $\mathrm{H} 12$ & H13 & & \\
\hline U-1 & $1: 20$ & 38 & 36 & 34 & 130 & 0.2 & 0.46 \\
\hline $\mathrm{U}-2$ & $1: 20$ & 46 & 64 & 42 & 152 & N.A. ${ }^{*}$ & N.A. \\
\hline U-3 & $1: 20$ & 56 & -- & 43 & 137 & N.A. ${ }^{*}$ & 2.2 \\
\hline U-4 & $1: 20$ & 41 & 45 & 38 & 126 & 0.2 & 0.49 \\
\hline S-5 & $1: 100$ & 31 & 3 & 15 & 12 & 4.4 & 2.2 \\
\hline S-6 & $1: 100$ & 26 & 19 & 21 & 10 & 4.5 & 0.22 \\
\hline S-7 & $1: 100$ & 26 & 19 & 20 & 9 & 4.4 & 0.038 \\
\hline $\mathrm{S}-8$ & $1: 100$ & 33 & 6 & 10 & 13 & 2.2 & 0.29 \\
\hline
\end{tabular}

two protons at $\mathrm{C}-12$ or $\mathrm{C}-13$. The saturated $\mathrm{N}$-hydroxypyridone ring is relatively flexible and exchanges between chair and boat conformations. Four saturated $\mathrm{N}$ hydroxypyridones had very similar $K_{d}$ values, in a tight range of $2-5 \mathrm{mM}$ (Table 1) which was 10 to 20 times larger than those of the unsaturated analogs. The overall chemical shift changes and the differences between the largest and the other perturbations of the core protons of the saturated compounds were both smaller than those observed with the unsaturated ones. We also observed the sharp-broad-sharp line-shape changes as the $\mathrm{Mg}^{2+}$ concentration increased, but didn't see the second binding of $\mathrm{Mg}^{2+}$ as well, probably because the $\mathrm{Mg}^{2+}$ concentration was not high enough.

\subsection{Ternary Complex of HIV-RH, $\mathrm{Mg}^{2+}$, and Metal-Chelating Compounds}

The use of metal chelation as an anchor to the active site is a common strategy in designing inhibitors to target HIV-RH and the highly- related HIV integrase enzymes $[2,16,32]$. The final product of the design is a ternary complex (compound/ metal-ion/protein). Therefore, the correlation between compound/metal or protein/metal binding affinity and enzyme inhibition is always of high interest. Sometimes, metal ions are critical for inhibition by the designed compound. $\beta$-thujaplicinol, a selective inhibitor of HIV RT, is a typical metal chelator [33]. Our study demonstrated that it binds to two $\mathrm{Mg}^{2+}$ ions sequentially. Its proton signals incrementally shifted downfield and became broader and broader as the concentration of $\mathrm{Mg}^{2+}$ increased. When the concentration of $\mathrm{Mg}^{2+}$ reached $8 \mathrm{mM}$, the signals started to shift in the opposite direction. As the $\mathrm{Mg}^{2+}$ concentration increased further, the signals shifted upfield and became narrower. The $K_{d}$ of $\beta$-thujaplicinol to the first $\mathrm{Mg}^{2+}$ ion, as determined from the proton chemical shift changes, is $0.64 \pm 0.10 \mathrm{mM}$. Interestingly, $\beta$-thujaplicinol introduced no chemical shift perturbations in the HSQC signals of the HIV-RH domain when metal ions were absent. On the contrary, in the presence of $8 \mathrm{mM} \mathrm{Mg}{ }^{2+}$, significant chemical shift perturbations were observed in the HSQC spectrum of the HIV-RH protein attributable to $500 \mu \mathrm{M} \beta$-thujaplicinol. The experiments indicated that the presence of a metal ion is necessary for $\beta$-thujaplicinol to interact with the HIV-RH domain, in agreement with the crystallographic results [21].

On the other hand, $500 \mu \mathrm{M}$ saturated tricyclic N-hydroxypyridone (compound s-7), which has a weak binding affinity $\left(K_{d} 4.4 \mathrm{mM}\right)$ to $\mathrm{Mg}^{2+}$, induced less than 25 $\mathrm{Hz}$ of chemical shift changes in the signals of 14 residues of HIV-RH in the presence of $8 \mathrm{mM} \mathrm{Mg}{ }^{2+}$. Three detectable chelating residuals of the DEDD motif, i.e., D443, E478 and D498, were among them. The chemical shift changes were 14, 10 and $13 \mathrm{~Hz}$, respectively. We also observed line-shape-broadening of the E478 signal. In comparison with Figure 1(c), Figure 4 indicates that the compound interacted with the active site of HIV-RH through $\mathrm{Mg}^{2+}$ chelation in the buffer containing $8 \mathrm{mM}$ $\mathrm{Mg}^{2+}$. Interestingly, in the absence of divalent metal ions, this compound was found to bind HIV-RH at an alternative binding site through our NMR and crystallographic studies (unpublished data). Although compound s-7 induced small chemical shift perturbations in the HIV-RH domain, it showed strong inhibition against HIV-RH with an $\mathrm{IC}_{50}$ of $0.038 \mu \mathrm{M}$. One reason could be that the experimental conditions used for the $\mathrm{IC}_{50}$ measurement were very different from those used in the NMR experiments. In our biochemical assay, we used substrate 


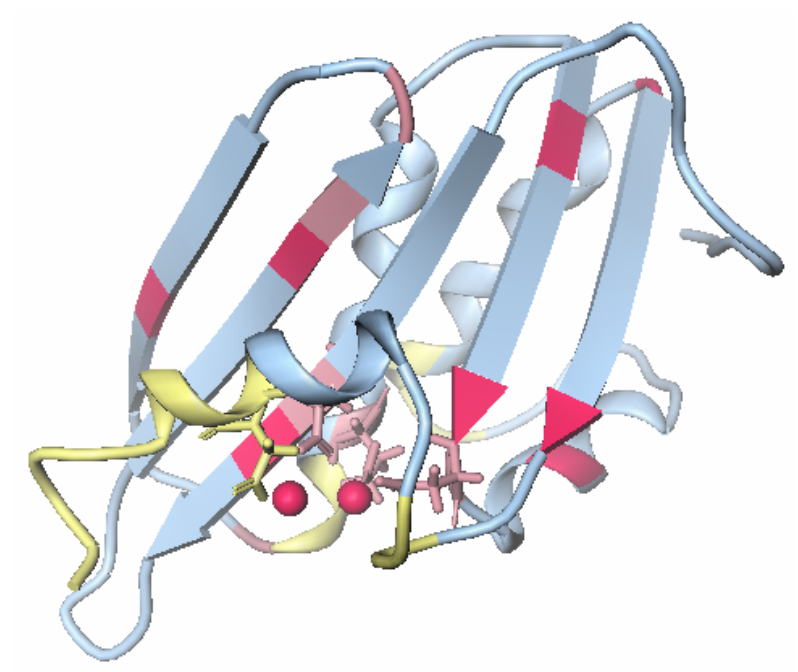

Figure 4. Mapping of the shift perturbations on the HIVRH structure by compound s-7 in the presence of $8 \mathrm{mM}$ $\mathrm{Mg}^{2+}$. The protein and compound concentrations are 72 and $500 \mathrm{M}$, respectively. Dark red: $\Delta \delta \geq 15 \mathrm{~Hz}$; light red: $\Delta \delta=$ 10 - 15 Hz.

oligonucleotides and full-length HIV-RT protein. Isolated HIV-RH domains have been either inactive or much less active in RNA hydrolysis than intact HIV-RT $[22,23,28,30]$. In addition, the interactions between RT and oligonucleotide duplexes may affect the conformation of the protein, thereby altering the affinity of RNase $\mathrm{H}$ for metal ions.

As shown in Table 1, we did not observe a correlation between the compound/metal chelating affinity and the anti-HIV-1 activity of the inhibitors. The interactions of $\mathrm{Mg}^{2+}$ with either HIV-RH or the tricyclic $N$-hydroxypyridones are weak, with $K_{d}$ values in the $\mathrm{mM}$ range. However, the HIV-RH $\mathrm{IC}_{50}$ of the tricyclic $N$-hydroxypyridone compounds range from $2.2 \mu \mathrm{M}$ to $0.038 \mu \mathrm{M}$. We believe that the metal-binding ability of this category of compounds plays an important role in anchoring the compound to the active site of HIV-RH specifically. Since the binding affinity of metal/compound and metal/ protein are weak, the inhibitory potency of the compound is not driven by metal chelation, but by direct interactions between the compound and the protein instead. Therefore, the goal of chemical design is to improve the inhibitory potency rather than to increase the metal chelation affinity. In fact, the strategy of focusing on protein/compound interaction is practically more efficient. Firstly, the protein/compound direct interaction is also the key to improve the selectivity of designed compounds. Secondly, very strong metal chelation property (for instance, in the low nM range) is not preferable because it may cause toxicity by chelating metal ions in the blood or in tissues.

\section{Conclusions}

To understand the correlation between metal-chelating properties and enzyme inhibition by metal-chelating inhibitors, we characterized the interactions of divalent metal ions with HIV-RH and two series of HIV-RH inhibitors using NMR chemical shift perturbations. We noticed that the chemical shift perturbation maps of the HIV-RH protein and the compounds are sensitive to the $\mathrm{pH}$, ionic strength and concentration of divalent metal ions. A neutral $\mathrm{pH}$ of 6.5 was chosen and $150 \mathrm{mM}$ salt was used to maintain the ionic strength in the metal ion binding studies. When the buffer $\mathrm{pH}$ and ionic strength were carefully maintained, the HSQC titration data demonstrated that $\mathrm{Mg}^{2+}$ and $\mathrm{Ca}^{2+}$ ions introduce small and localized chemical shift perturbation patterns in HIV-RH. Both $\mathrm{Mg}^{2+}$ and $\mathrm{Ca}^{2+}$ bind specifically to the active site of the HIV-RH domain, with binding constants of 13 and $3 \mathrm{mM}$, respectively. We also observed that two $\mathrm{Mg}^{2+}$ ions bind sequentially to the RNase $\mathrm{H}$ domain, whereas only a single binding event was observed for $\mathrm{Ca}^{2+}$ ions.

The metal-chelating affinities of the saturated or unsaturated tricyclic $N$-hydroxypyridone inhibitors were also measured and compared. Compounds that contain the same tricyclic core showed similar binding affinity to metal ions at the same primary chelating site. Metal ions interact primarily at site $I$ with the unsaturated tricyclic $\mathrm{N}$-hydroxypyridones, but at site $\mathrm{II}$ with the saturated analogs (Figures 3(a) and (b)). The flexibility of the $N$-hydroxypyridone ring gained from the saturation reduced the metal-binding affinity from 0.2 to $4.0 \mathrm{mM}$.

With $8 \mathrm{mM} \mathrm{Mg}^{2+}$ present, our NMR mapping data demonstrated that the tricyclic $N$-hydroxypyridone compounds bind to the active site of HIV-RH. Interestingly, regardless of the weak interaction of $\mathrm{Mg}^{2+}$ with either HIV-RH target or the tricyclic $N$-hydroxypyridones (the $K_{d}$ 's are in the $\mathrm{mM}$ range), the HIV-RH $\mathrm{IC}_{50}$ of those compounds were much higher, from $2.2 \mu \mathrm{M}$ to $0.038 \mu \mathrm{M}$. The poor correlation between the compound/metal chelating affinity and the anti-HIV-1 activities of the inhibitors reveals the direct protein/compound interactions of the series of inhibitor. The metal-binding property is necessary for the metal chelating inhibitors to bind specifically to the active site through a metal ion bridge, but the design should focus on the direct interactions of the compound with the protein for inhibitory potency and selectivity.

\section{Acknowledgements}

The authors thank Dr. Cathy Moore for her valuable discussions and comments. 


\section{References}

[1] E. J. Artsa and S. F. Le Grice, "Interaction of Retroviral Reverse Transcriptase with Template-Primer Duplexes during Replication," Progress in Nucleic Acid Research and Molecular Biology, Vol. 58, 1997, pp. 339-393. doi:10.1016/S0079-6603(08)60041-0

[2] V. Goldschmidt, J. Didierjean, B. Ehresmann, et al., " $\mathrm{Mg}^{2+}$ Dependency of HIV-1 Reverse Transcription, Inhibition by Nucleoside Analogues and Resistance," Nucleic Acids Research, Vol. 34, No. 1, 2006, pp. 42-52. doi:10.1093/nar/gkj411

[3] M. Götte, "Inhibition of HIV-1 Reverse Transcription: Basic Principles of Drug Action and Resistance," Expert Review of Anti-Infective Therapy, Vol. 2, 2004, pp. 707-716. doi:10.1586/14789072.2.5.707

[4] M. Götte, S. Fackler, T. Hermann, et al., "HIV-1 Reverse Transcriptase-Associated Rnase H Cleaves RNA/RNA in Arrested Complexes: Implications for the Mechanism by Which Rnase H Discriminates between RNA/RNA and RNA/DNA," EMBO Journal, Vol. 14, No. 4, 1995, pp. 833-841.

[5] S. J. Schultz and J. J. Champoux, "RNase H Activity: Structure, Specificity, and Function in Reverse Transcription," Virus Research, Vol. 134, No. 1-2, 2008, pp. 86-103. doi:10.1016/j.virusres.2007.12.007

[6] M. Nowotny and W. Yang, "Stepwise Analyses of Metal Ions in Rnase H Catalysis from Substrate Destabilization to Product Release," EMBO Journal, Vol. 25, No. 9, 2006, pp. 1924-1933. doi:10.1038/sj.emboj.7601076

[7] W. Yang, J. Y. Lee and M. Nowotny, "Making and Breaking Nucleic Acids: Two- $\mathrm{Mg}^{2+}$-Ion Catalysis and Substrate Specificity," Molecular Cell, Vol. 22, No. 1, 2006, pp. 5-13. doi:10.1016/j.molcel.2006.03.013

[8] M. Nowotny, S. A. Gaidamakov, R. J. Crouch, et al., "Crystal Structures of RNase H Bound to an RNA/DNA Hybrid: Substrate Specificity and Metal-Dependent Catalysis," Cell, Vol. 121, No. 7, 2005, pp. 1005-1016. doi:10.1016/j.cell.2005.04.024

[9] J. A. Cowan, T. Ohyama, K. Howard, et al., "Metal-Ion Stoichiometry of the HIV-1 RT Ribonuclease H Domain: Evidence for Two Mutually Exclusive Sites Leads to New Mechanistic Insights on Metal-Mediated Hydrolysis in Nucleic Acid Biochemistry," Journal of Biological Inorganic Chemistry, Vol. 5, No. 1, 2000, pp. 67-74. doi:10.1007/s007750050009

[10] J. Q. Hang, S. Rajendran, Y. L. Yang, et al., "Activity of the Isolated HIV Rnase H Domain and Specific Inhibition by N-Hydroxyimides," Biochemical and Biophysical Research Communications, Vol. 317, No. 2, 2004, pp. 321329.

[11] K. Pari, G. A. Mueller, E. F. Derose, et al., "Solution Structure of the Rnase H Domain of the HIV-1 Reverse Transcriptase in the Presence of Magnesium," Biochem, Vol. 42, No. 3, 2003, pp. 639-650. doi:10.1021/bi0204894

[12] K. Katayanagi, M. Okumura and K. Morikawa, "Crystal
Structure of Escherichia Coli Rnase HI in Complex with $\mathrm{Mg}^{2+}$ at 2.8 a Resolution: Proof for a Single Mg(2+)-Binding Site," Proteins, Vol. 17, No. 4, 1993, pp. 337-346. doi:10.1002/prot.340170402

[13] M. Nowotny, S. A. Gaidamakov, R. Ghirlando, et al., "Structure of Human Rnase H1 Complexed with an RNA/DNA Hybrid: Insight into HIV Reverse Transcription," Molecular Cell, Vol. 28, No. 2, 2007, pp. 264-276. doi:10.1016/j.molcel.2007.08.015

[14] O. Schatz, F. V. Cromme, F. Grüninger-Leitch, et al., "Point Mutations in Conserved Amino Acid Residues within the C-Terminal Domain of HIV-1 Reverse Transcriptase Specifically Repress RNase H Function," FEBS Letters, Vol. 257, No. 2, 1989, pp. 311-314. doi:10.1016/0014-5793(89)81559-5

[15] S. F. Le Grice, T. Naas, B. Wohigensinger, et al., "Subunit-Selective Mutagenesis Indicates Minimal Polymerase Activity in Heterodimer-Associated P51 HIV-1 Reverse Transcriptase," The EMBO Journal, Vol. 10, No. 12, 1991, pp. 3905-3911.

[16] K. Klumpp and T. Mirzadegan, "Recent Progress in the Design of Small Molecule Inhibitors of HIV RNase H," Current Pharmaceutical Design, Vol. 12, No. 15, 2006, pp. 1909- 1922. doi: $10.2174 / 138161206776873653$

[17] E. Tramontano, "HIV-1 RNase H: Recent Progress in an Exciting, Yet Little Explored, Drug Target," Mini-Reviews in Medicinal Chemistry, Vol. 6, No. 6, 2006, pp. 727-737. doi:10.2174/138955706777435733

[18] G. M. Clore and A. M. Gronenborn, "Multidimensional Heteronuclear Nuclear Magnetic Resonance of Proteins," Methods in Enzymology, Vol. 239, 1994, pp. 349-363. doi:10.1016/S0076-6879(94)39013-4

[19] S. Grzesiek and A. Bax, "Amino Acid Type Determination in the Sequential Assignment Procedure of Uniformly $13 \mathrm{C} / 15 \mathrm{~N}$-Enriched Proteins," Journal of Biomolecular NMR, Vol. 3, No. 2, 1993, pp. 185-204.

[20] D. Goddard and D. G. Kneller, "SPARKY 3," University of California, San Francisco, 2000.

[21] D. M. Himmel, K. A. Maegley, T. A. Pauly, et al., "Structure of HIV-1 Reverse Transcriptase with the Inhibitor Beta-Thujap- licinol Bound at the RNase H Active Site," Structure, Vol. 17, No. 12, 2009, pp. 1625-1635. doi:10.1016/j.str.2009.09.016

[22] A. Jacobo-Molina, J. Ding, R. G. Nanni, et al., "Crystal Structure of Human Immunodeficiency Virus Type 1 Reverse Transcriptase Complexed with Double-Stranded DNA at 3.0 a Resolution Shows Bent DNA," Proceedings of the National Academy of Sciences of the USA, Vol. 90, No. 13, 1993, pp. 6320-6324.

[23] J. L. Keck and S. Marqusee, "The Putative Substrate Recognition Loop of Escherichia Coli Ribonuclease H Is Not Essential for Activity," Journal of Biological Chemistry, Vol. 271, No. 33, 1996, pp. 19883-19887. doi:10.1074/jbc.271.33.19883

[24] G. A. Mueller, K. Pari, E. F. Derose, et al., "Backbone Dynamics of the Rnase H Domain of HIV-1 Reverse Transcriptase," Biochem, Vol. 43, No. 29, 2004, pp. 
9332-9342.

[25] Y. Oda, H. Nakamura, S. Kanaya, et al., "Binding of Metal Ions to E. coli Rnase HI Observed by $1 \mathrm{H}-15 \mathrm{~N}$ Heteronuclear 2D NMR," Journal of Biomolecular NMR, Vol. 1, No. 3, 1991, pp. 247-255. doi:10.1007/BF01875518

[26] Y. Oda, H. Nakamura and S. Kanaya, "Role of Histidine 124 in the Catalytic Function of Ribonuclease HI from Escherichia coli," Journal of Biological Chemistry, Vol. 268, No. 1, 1993, pp. 88-92.

[27] R. Powers, G. M. Clore, A. Bax, et al., "Secondary Structure of the Ribonuclease H Domain of the Human Immunodeficiency Virus Reverse Transcriptase in Solution Using Three-Dimensional Double and Triple Resonance Heteronuclear Magnetic Resonance Spectroscopy," Journal of Molecular Biology, Vol. 221, No. 4, 1991, pp. 1081- 1090.

[28] R. Powers, G. M. Clore, S. J. Stahl, et al., "Analysis of the Backbone Dynamics of the Ribonuclease H Domain of the Human Immunodeficiency Virus Reverse Transcriptase Using 15N Relaxation Measurements," Biochem, Vol. 31, No. 38, 1992, pp. 9150-9157. doi:10.1021/bi00153a006

[29] D. Chattopadhyay, B. C. Finzel, S. H. Munson, et al., "Crystallographic Analyses of an Active HIV-1 Ribonu- clease H Domain Show Structural Features That Distinguish It from the Inactive Form," Acta Crystallographica Section D: Biological Crystallography, Vol. 49, 1993, pp. 423-427. doi:10.1107/S0907444993002409

[30] J. F. Davies, Z. Hostomska, J. Hostomsky, et al., "Crystal Structure of the Ribonuclease H Domain of HIV-1 Reverse Transcriptase," Science, Vol. 252, No. 5002, 1991, pp. 88-95. doi:10.1126/science. 1707186

[31] J. Jäger, S. J. Smerdon, J. M. Wang, et al., "Comparison of Three Different Crystal Forms Shows HIV-1 Reverse Transcriptase Displays an Internal Swivel Motion," Structure, Vol. 2, No. 9, 1994, pp. 869-876. doi:10.1016/S0969-2126(94)00087-5

[32] J. A. Grobler, K. Stillmock, B. Hu, et al., "Diketo Acid Inhibitor Mechanism and HIV-1 Integrase: Implications for Metal Binding in the Active Site of Phosphotransferase Enzymes," Proc. Natl. Acad. Sci. USA, Vol. 99, No. 10, 2002, pp. 6661-6666. doi:10.1073/pnas.092056199

[33] S. R. Budihas, I. Gorshkova, S. Gaidamakov, et al., "Selective Inhibition of HIV-1 Reverse Transcriptase-Associated Ribonuclease H Activity by Hydroxylated Tropolones," Nucleic Acids Research, Vol. 33, No. 4, 2005, pp. 1249-1256. doi:10.1093/nar/gki268 